I.

UCID. 19123

\title{
Human Factors Engineering Design Review Acceptance Criteria for the Safety Parameter Display
}

Vincent McGevna

L. Polf Peterson

October 2, 1981

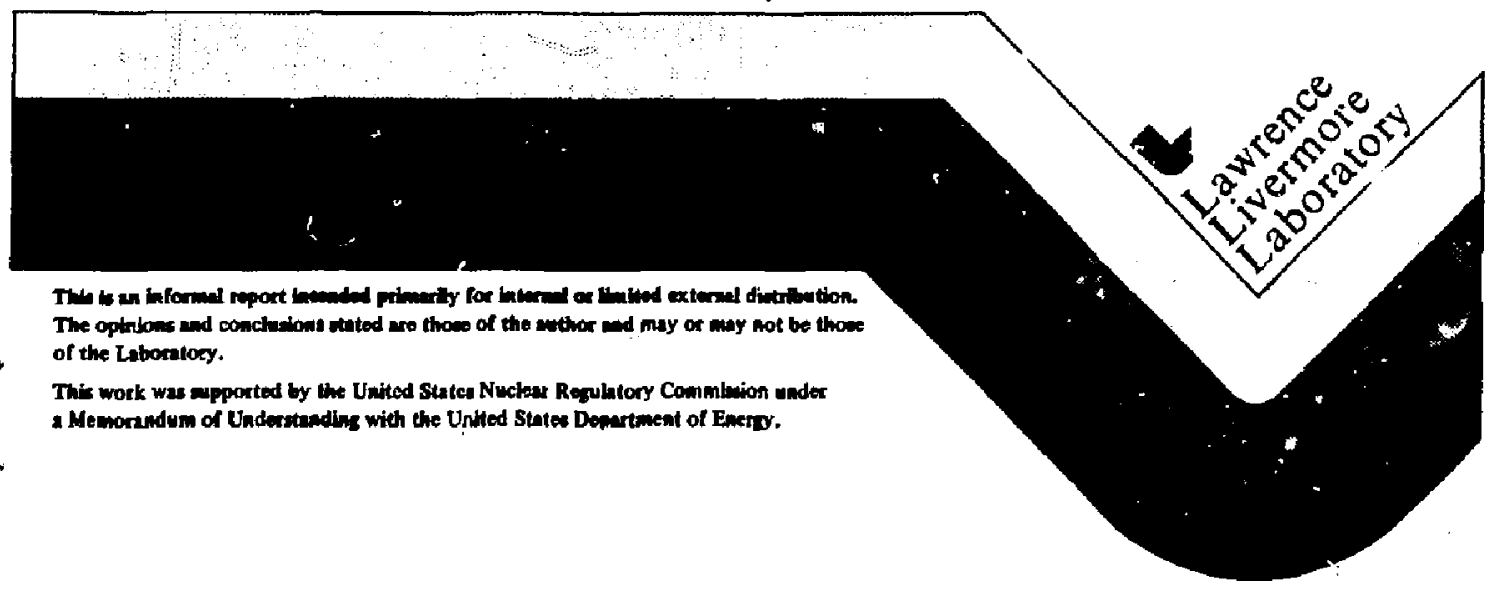

BST? 
UCID -19123

DE82 010707

\section{ABSTRACT}

This report contains human factors engineering disign review acceptance criteria developed by the Human Factors Engineer.ng Branch (HFEB) of the Nuclear Regulatory Commission (NRC) to use in evaluating designs of the Safety Parameter Display System (SPOS). These criteria were developed in rosponse to the functional design criteria for the SPDS defined in NUREG-0696. Functional Criteria for Emergency Response Facilities.

The purpose of this report is to identify design review acceptance criteria for the SPDS installed in the control room of a nuclear power plant. Use of computer driven cathode ray tube (CRT) displays is anticipated. General acceptance criteria for displays of plant safety status information by the SPDS are developed. In addition, specitic SPOS review criteria corresponding to the SPDS functional criteria specified in NUREG-0696 are established.

These design review acceptance criterja define a basis for the NRC staff's human factors review of a Safety Parameter Display System. These review criteria do not impose any new functional design requirements.

Issuance of NUREG-0835 daes not presuppose Of fice of Management and Budget (OMB) approval of any reporting requirements associated with the detailed SPDS design guidelines in NUREG-0696. Accordingly, the guidance in NUREG-0835 is preliminary in nature and subject to possible changes that may result from an OMB review under the Paperwork Reduction Act of 1980.

This draft report is issued to encou, age public and industry comment. The staff will evaluate all comments it receives and modify the report as needed in preparing the final report. Comments received by the Commission will be made available for public inspection at the Commission's Public Document Room in Washington, D.C. All comments on this draft report must be provided by the day of the month following the publication month of this report. comments shculd be forwarded to:

Mr. Voss A. Moore, Chief Human Factors Engineering Branch Division of Human Factors Safety U.S. Nuclear Regulatory Commission Washington, D.C. 10555

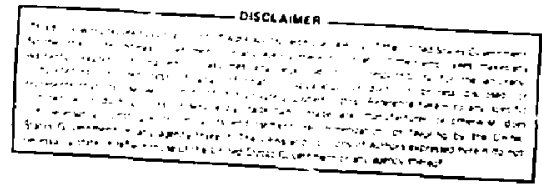




\section{CONTENTS}

\section{Page}

1.0 Introduction

2.0 Scope

3.0 General Acceptance Criteria for SPDS Displays

3.1 Detection of Abnormal Conditions

3.2 SPDS Data Display Formats

3.3 Display Techniques

3.3.1 Display Patterns

3.3.2 Scaling of Displays

3.3.3 Identification of Displayed Parameters

3.3.4 Perceptual Aids

4.1: Specific SPOS Design Review Acceptance Griteria ?

4.1 Functions

4.1.1 Primery Function

4. P.E Secomuary Fumetions

4.13 Fut ure Functions

4.2 Data Set

4.2.1 Basis of Parameter Selection

4.3 Data Validation

4.3.1 Real Time Validation

4.3.2 Unvalidated Data

4.4 Display

4.4.1 Design Principles

4.4.2 Parameters Displayed

4.4.3 Pattern and Coding

4.4.4 Additional Daia

4.4.5 Mode of Operation

4.5 Location and Readability

4.5.1 Display Location

4.5.2 Control Board

23

4.5.3 Display Readabiticy 24

4.5.4 Display Accessibility 25

4.5.5 Control Accessibility 26

27

4.6.T Control koom Statr

4.6.2 Operator Interaction 27

$\begin{array}{lll}4.7 & \text { Procedures } & 28\end{array}$

4.7.1 Failure Recognition 28

4.7.2 Technical Specification 29

4.8 Audible Al arms $\quad 30$

4.9 Design Criteria 31

4.9.1 Functional Qualification 31

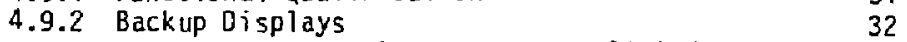

4.9.3 Primary Display, Seismically qualified 33

5.0 Human Factors Eng ineering Review Process 34

5.1 Review of Verification of Design 34

5.2 Reveiw of Validation of Functional Operation 35

$\begin{array}{ll}5.3 \text { Review Methads } & 35\end{array}$

6.0 References 37

Appendix A Application of General Criteria to Display Patterns A-1 


\section{I.0 INTROOUCTJON}

The accident at Three Mile Island (TMI) and subsequent investigations have demonstrated the need for improving the presentation of plant and process information to reactor operators. This is especially true when a nuclear power plant undergoes a major transient. A major transient, such as the one at TMI, may develop slowly over an extended period of time. During a major transient, a reactor operator is required to monitor and process large amounts of data to ascertain the operating status and safety status of the plant.

NUREG-0596, Functional Criteria for Emergency Response Facilities (Ref. 1), describes Emer'gency Response Facilities (ERFs) that are designed to improve emergency response to an accident at a nuc lear power plant. MUREG-0814, Methodology for Evaluation of Emergency Response Facilities, (a draft report for public comment), defines questions that will be used by the ARC staff to review canceptual designs for the ERFs. The Saiety Parameter Display System (SPDS) is described in NUREG-0696. The SPDS will display a minimum set of plant parameters from which the safety status of $p$ lant operation may be assessed by reactor operators. The SPDS and the control room operating crew as a unit should be able to detect abnormal operating conditions that could adversely affect the safety of the plant. Section 5 of NUREG-0696 gives the functional criteria which the SPDS should meet.

These design review acceptance criteria define a basis for the NRC staff review of a Safety Parameter Display System. Use of other design review acceptance criteria that may exist is acceptable provided it is shown that the SPDS functional design criteria are satisfied. These review criteria do not impose any new funct ional design requirements.

Design specifications of SPOS systems and displays are not explicit in either the functional criteria of NUREG-0596 or the NRC regulations. Those examples of displays given in this report are provided to help designers, licencees/applicants, and reviewers interpret the design review acceptance criteria.

\subsection{SCOPE}

This document presents oniy SPDS design review acceptance criteria that are within the scape of review related to human factors engineering. The human factors eng ineering review covers about one-half of the SPDS functional criteria stated in NUREG-0696. The remaining functiona 7 criteria will be reviewed in accordance with existing NRC guidance.

The design review acceptance criteria emphasize review of SPDS designs that use computer driven cathode ray tube (CRT) displays. This approach reflects the types of SFDS designs proposed by the nuclear industry in most of the technical briefings presented to the NRC regulatory staff. It also reflects the general trend in the nuclear industry toward increased use of CRT displays. 
Present functional criteria for the SPDS do not rule out the use of other types of displays in SPOS designs. These criteria generally apply to all types of SPOS displays with special emphasis on some aspects of CRT displays. It was time and cost effective for the staff to develop acceptance criteria with emphas is on the computer driven CRT displays proposed by industry. More specific design review acceptance criteria for other types of SPDS display designs will be developed and defined case by case as designs are submitted for review.

NUREG-0700, Guidelines for Control Room Design Reviews, (Ref. 2), are applicable for human factors engineer ing review of visual displays, process computers, and CRT displays. The NUREG-0700 guidelines alone are not sufficient to review an SPDS and assure that the SPDS functional requirements developed in NUREG-0696 are met. Therefore, it was necessary to develop additional design review acceptance criteria that apply to the SPOS functional requirements. These SPDS acceptance criteria provide the bas is for a review of SPDS displays without 1 imiting the types of acceptable SPDS displays to computer driven CRT displays.

General spos display criteria are defined and discussed in Section 3.0, General Acceptance Criteria for SPDS Displays. Then the functianal criteria published in NUREG-0696 are organized into specific topic areas and design review acceptance criteria are defined for each functional criterion. These specific criteria are defined in Section 4.0, Specific SPOS Design Review Acceptance Criteria.

A reviewer should be familiar with the human factors guidelines in MUREG-0700. The most important of these guidelines are Section 6.5, visua? Displays, which includes principles ot display, meters, light indicators, and araphic recorders; Section 6.6, Labels and Location Aids, which includes labeling principles, label location, label content, and location aids; Section 6.7, Process Computers, which includes computer access, CRT displays, and printers; and Section 6.8, Panel Layout, which includes pane] contents, recognition and identification er' 'ncement, and layout arrangement factors. Review criteria references to NURcu-0700 are made only where thuse human engineering guidelines are directly applicable to the review acceptance criteria.

A reviewer of SFLS systems also should be familiar with CRT technolagy and its application to nuc lear power systems. Several references provide general information on the design of CRT-based display systems (Reis. 3-5). A document detaj]ing human engineering design data for CRT baseo display systems is current iy being developed by an NRC contractor (Ref. 6). This forthcoming document wi $\}$ i be useful for reviewing many aspects of an SPOS design that uses CRT displays. However, a detailed comparison of this document with the contral room human engineering guidelines guidelines presented in NUREG -0700 has not been conducted. Another recent NRC contractor report (Ref. 7) presents numerous ways of displaying multivariate data for use in nuclear process control. Although this repart draws some conclusions on the applicability of various displays in reactor cantrol rooms for process control applications, these conclusions do not necessarily apply to specialized functional requirements for SPOS displays. All of these references contain extensive bibliographies for reference to mare specific information. 
In summary the NUREG-0700 design guidelines are not necessarily the only acceptable guidelines which may be appl ied to the SPDS design reviews.

Additiona? guidelines provided in the listed references or elsewhere which are exceptions to the NUREG 0700 guidelines may be equally acceptable provided the SPOS functional criteria are met. The source of these other acceptance criteria should be cited and justification for the ir use should be provided to the reviewer.

\subsection{GENERAL ACCEPTANCE CRITERIA FOR SPDS DISPLAYS}

The primary function of the SPDS is to help control room operating personnel make quick assessments of the plant safety status. The display should be monitored by the operators during normal operations in the course of performing assigned monitoring functions. During emergencies, the SPOS should serve as an aid to the control room operating crew in executing the symptom oriented emergency procedures. In this primary function, the SPOS provides the reactor operators plant status information from an integrated display during normal and tmergency conditions in a manner analogous to the way the basic attitude and flight performance instruments of an ajrcraft provide a ircraft status informztion to the pilot. The SPOS and the control room operators as a unit should be able to detect abnormal conditions that could have safety significance.

Operators must be trained in the use of the SPDS. The human operator is the key subsystem in the: plant that can synthesize the plant process and assess the important $p l a n t$ functions fron the data provided on the display. The displayed data is read and proceised by the operator to determine the plant status. The design of the SPDS display should cansider the operator's needs and should use perceptual aids that assist the operator in the plant synthesis and decision making tasks. A functional qualification program that demonstrates enhanced operator performance in correctly assessing safety status of the plant will be a key factor in the NAC review and acceptance of SPOS designs.

NUREG-0696 states that the SPDS should display a minimum set of plant parameters from which the safety status of the plant may be assessed. The minimum set of parameters was not defined. The staff recognized that the minimum set of parameters may be plant dependent. However, NUREg-0696 did define important plant functions to include, but not be limited to:

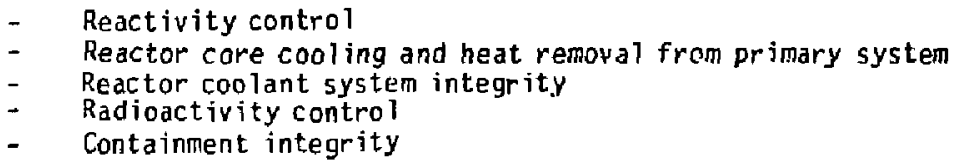

Other plant functions may also be important. The primary display of the SPDS should consist of the minimuin set of parameters from which the operator can assess the plant safety status. The status and performance of systems, subsystems, and components should be allocated to secondary display formats if this information is oart of the SPQS data. 
The mechanism for displaying the spos safety information is not rigidly specified by the functional requirements of NUREG-0696. The plant safety status iniormation must be presented by the SPOS to enhance the functional effectiveness of contro ? room personnel. Good human factors engineering of the SPDS is a functional requirement. It is anticipated that SPDS designs generally will use computer driven CRT displays since they al low more flexibility in data display format and data display enhancement than do analog meters and analog chart recorders. This display may consist of one or more CRTs as needed to meet the functions of the design. However, the use of non-CRT types of displays in not precluded. These review criteria are nat intended to be so restrictive that they eliminate consideration of other useful displays that are presently available or that may be developed as techniques for data presentation evolve.

\subsection{Detection of Abnormal Conditions}

The SPDS is to provide an indication of plant parameters or derived variables representative of the safety status of the plant and is to aid the operator in the $r$ apid detection of abnormal operating conditions significant to safety. A minimum set of plant parameters from which the plant safety status can be assessed are to be grouped in the SPDS display. The technical choice of the appropriate minimum set of plant parameters to be used by the SPDS is beyond the scope of these human factors design review acceptance criteria.

The display of abnormal operating conditions significarit to safety must be distinctly different in appearance from the djsplay depicting normal operating conditions. This distinction is to assist the control room operating crew in detecting abnormal operating conditions. Displays that present the minimum set of plant safety status parameters in a format that is readily interpretable by the operators and that is visible to the operators are acceptable.

Acceptable SPDS designs will assist operators io rapidly detect an abnormal condition and will assist in initiating diagnosis to localize the source of the abnormality at the function or system level. Such designs witi enable operators to specificai?y jdentify what safety status parameters a re abnormal.

\subsection{SPDS Data Display Formats}

The functional requirements specify that the SPDS must display the minimum set of plant parameters or derived variables and their trends in a single primary fisplay format for each mode of plant operation. A common display format composed of the same plant parameters may be used for several modes of plant operation. However, the display must contain that minimum set of parameters needed to assess the safety status of the plant for each mode of operation. The SPOS may also have the capability to recall additional data on secondary display formats or displays. Acceptable SPOS display formats may present plant safety status information in combinations of alphanumeric, symbolic, or graphic form and may present plant parameter data in analog or digital form. 
The frimary display format may be presented on a single display device or a graup of display devices concentrated in a single compact display at a location specifically designated for the SPDS. Primary display formats that remain continuously visible to the operators are acceptable.

The information displayed by the SPOS display must be presented in ways that are easy for the operators to read and understand. Display formats designed so that specif ic elements in the display correspond directly and unambiguousiy with each parameter are acceptable. A label or other readily understood identifier that appears on each element of the display and specifically identifies that element with the parameter it represents is acceptable.

Changes in value of a display element should be readily interpreted as a corresponding change in the magnitude of the measured or derived parameter. In most cases a linear relationship between the magnitude of the measured or derived value of the parameter and the display element used to depict the parameter is acceptable. In some cases a nonlinear relationship between the parameter and the display e Tement may be acceptable if it can be demonstrated that such a relationship is more meaningful to the operators or that it will actually facilitate interpreting information. For example, a logarithmic relationship between reactor power level and the magnitude of the corresponding display element may be appropriate to display power during reactor startup if accurate readings of reactor power are needed over many decades of power level.

Quantitative information about the magnitude and trend behavior of the parameters used for the SPDS must be presented to he 1p the operators assess the severity of abnormal $p l a n t$ conditions. Displays that provide quantitative data of the magnitude of each parameter on the primary display as part of the primary display format are acceptable. Properly designed numeric, analog, or graphic displays of parameter magnitude are acceptable.

In addition to magritude, the operators should also be able to determine whether each parameter is increasing or decreasing and abserve the trend or rate of change of a parameter from changes in the display. Operator monitoring of parameter trends is a key task in evaluating the safety status of the plant. This trend information is needed to assist the operators in determining the severity of a abnormality when a transient condition develops.

Primary SPDS displays that show quantitative rate of change information are acceptable provided the quantitative rate of change display will not be misleading to the operators during transient or oscillatory variations of the parameter that may occur. Primary SPOS displays that provide qualitative trend and rate of change information by observation of the variation in magnitude of the parameters are acceptable if quantititative rate of change and time history data for each parameter are available on a secondary SPDS display.

Time history displays of parameters over a recent time interval are a preferred means of displaying trend and rate of change data. A time history of each safety status parameter for the 30 minutes immediately preceeding current real time is acceptable. This time period is consistent with the startup time required for activating the Technical Support Center (TSC). Availability of time history data displays on either the prinary SPDS display format or on a secondary SPOS display format is acceptable. 


\subsection{Display Techniques}

Since the primary function of the SPDS is to assist control room operating personnel in evaluating the safety status of the plant, the display should be enhanced to improve the operator's perception, comprehension, and detection of abnormal operating status significant to safety. Some display design techniques to enhance the detection function are discussed in the following sections. Review guidance is provided for each technique to assure that use of that technique will provide acceptable enhancement features for the SPDS display.

The display enhancement techniques discussed are:

1. Display Patterns

2. Scaling of Displays

3. Ident if ic ation of Displayed Parameters

4. Perceptual Aids

1. Color

2. Syinbols and mimics

3. Overlays

4. Setpoints

5. Bitinking and Flashing

Dispiay techniques other than those listed ray aiso be acceptat?e.

\subsubsection{Display Patterns}

Patterns can be an effective way to present data to an operator. When a pattern is used to enhance the operators " assessment of the safety status of the $p l$ ant there should be a direct association between the display pattern and the status of the plant.

The pattern for normal operating conditions should have distinctive characteristics that distinguish it from the patterns produced by abnormal conditions. The change from normal to abnormal pattern configuration should be readily detectable. One change in pattern that is acceptahle when properly designed and implemented is a change from a symetric or regular geometric pattern during normal operating conditions to an asymetric or irregular geometric pattern when an abnormal condition occurs. Another change in pattern that may be acceptable is a change from a pattern displaying uniform magnitude or length of all pattern elements during normal conditions to a pattern displaying unequal magnitudes or lengths of pattern elements representing parameters that are in an abnormal state.

\subsubsection{Scaling of Displays}

The displays of parameter magnitude should be scaled to optimize the operator recognition of plant chanjes from normal conditions. The choice of a parameter scale to produce an undistorted display pattern under norma] conditions is an acceptable scaling technique provided adequate data readout accuracy for operator use is maintained. However, it may not be possible to normalize all parameters. 
Parameter magnitude should be scaled to allow tracking over a wide range of abnormal conditions. Patterns for abnormal conditions that do not fill the entire display area are acceptable. Pattern displays that i:ave means of reading parameter data if the display pattern should go offscale during abnormal conditions are also acceptable.

An operator is not likely to notice small changes in a pattern which normally appears distorted. During normal operation, a parameter being displayed may deviate from its nominal value. However, it is importarit that the display pattern remain undistorted to avoid giving false indication of abnormality to the operator. Displays should use appropriate parameters that have small deviations about a steady state value during normal operating conditions and that have distinctive iarge variations from the steady state value during abnormal conditions.

It may be acceptable to change the scaling factors used in a display if changes in relative magnitudes of the parameters occur during plant operations. For example, normal operation at reduced power may result in a display which appears distorted relative to the display exhibited during operation at $100 \%$ power. Since reduced power operation does not represent an abrormal condition, a change in display scale may be acceptable to provide a display that remains undistorted. Il is preferable that this type of display scaling change on $7 y$ be made by operator command rather than by automat ic action of the display signal or data processing system to assure that an abnormal condition is not micrepresented by the SPDS display system.

\subsubsection{Identification of Displayed Parameters}

The operator must be able to readily interpret the information conveyed by the SPDS risplay. When a display changes, the operator must know what parameters are cr anging and how they are cha...jing in order to assess the nature of an abnormality. This will also help ident ify the system involved during an abnormal condition. An acceptable display format or display pattern must inciude labe is to identify each parameter. Reliance upon the operator's memorization of the relationship between the display format or the display pattern and the specific variables being displayed is not acceptable.

\subsubsection{Perceptual Aids}

Perceptual aids can be used with all types of display mechanisms. Among the perceptual aids suitable for use in SPDS dispiays are color, symbo's, overlays, and setpoints.

\subsubsection{Color}

Color may be used in SPOS displays to help identify and differentiate between elements of the display and to indicate a change in functional or operating status of a plant parameter. To be effective, the colors used in the SPDS display should conform to a color code. Conformance with the guidelines provided by NUREG-0700, Section 6.5.7.6, Color Coding, and Section 6..7.2.7, Graphic Eoding and Highlighting is acceptable for SPDS displays.

$$
-7-
$$


When color changes are used to indicate a change in functiond or operating status, they should be limited to no mare than two levels in severity of the change in status. Acceptable displays may employ one color change when a parameter is outside its normal range but does not represent a serious problem. A second more noticeab le color change when a parameter is in a range that indicates a serious abnormality is a lso acceptable. Use of the preferred color codes in NUREG-0700 to depict alerting and alarming conditions of parameters being displayed is acceptable.

Acceptable displays will avoid corflicts between the use of color to enhance identification of dispiay elements and the use of color to enhance changes in status of displays or display elements.

\subsubsection{Symbols and Mimics}

Graphic symbols and mimics may be used as distinctive means of presenting information in a pictorial format. Conformance with the guidelines of NUREG-0700, Section 6.6.3.4, Symbols, and Section 6.6.6.4, Use of Mimics, is acceptabie for SPDS displays.

\subsubsection{Overlays}

Overlays $c$ an be an effective means of enhancing displays. An overlay which provides a reference to normal conditions, or provides an indication of norma? limits for individual parameters, or provides an indication of abnormal operating ranges is acceptable. An overlay of a normal pattern can enhance some graphic displays by providing a reference to uormal operating conditions to facilitate pattern recognition or to detect deviation from norma ? ronfitions. Electronic overlays for CRT displays are acceptable when they improve the operator's interpretation of the operating conditions. Transpare,it overlays that interfere with observation or interpretation of plant aperating conditions are not acceptable.

\subsubsection{Setpoints}

Setpoints for a parameter that are used to initiate changes in display presentation and to alert operators to changes in operating status are acceptabie. Setpoints used for display changes and overiays must be estabijshed using appropriate technical considerations. Arbitrarily establishing setpoints as some nominal percentage of normal value or maximum range will not necessarily provide any display enhancement. Poorly chosen setpoints $c$ an have negative effects if they result in frequent false alarms. Setpoints used for display enhancenent that are chosen specificaliy for the ir appropriateness to perform that furiction are acceptable. A. uitrarily setting a setpoint at some fixed fraction of the normal operating value without supporting justification is not acceptable. 


\subsubsection{Blinking and Flashing}

Blinking of symbols or data on a CRT, blinking of illuminated graphic Jisplays, and flashing of, indicator lights ancimunc ator displays are effective and acceptable mearis of cailing opertor attention to an abnormal condition. Conformance with the guidelines of NUREG 0700 , Section 6.3 .3 .2 , Visual Alarm Recognition and Identification, and ith Section 6.7.2.7, Graphic Coding and Hightighting is also acceptable for use in SPOS displays.

\subsection{SPECIFIC SPDS DESIGN REVIEW CRITERIA.}

The specific design review acceptance criteria address all SPDS display systems with emphas is on review criteria applicable to CRT display systems. The SPOS : unctional criteria, as defined in Section 5 of NUREG-0696, have been grouped into nine broad categories.

These categories are:
1) Functions,
2) Data St:.
3) Dața Validation,
4) Dispiay,
5) Location and Size,
6) Staff,
7) Procedures,
8) Alarms,
9) Design Criteria.

The iunctional design criteria for each category are stated and referenced to NUREG-0695. Specific design reviem acceptance criteria are presented fer each functional criterion and are referenced to NUREG-0700, Section 6., Control Room Human Engineering Guidelines, where applicable. 


\subsection{FUNCTIONS}

\subsubsection{Primary function}

The primery furiction of the SPOS is to se: ve as an operator aid in the rapid detection of abnorma? conditions by providing a display of plant parameters from which the safety status of aperation may be assessed in the control room.
5.1

1.3 .4

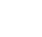

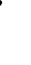




\subsubsection{Future Functions}

The design of the display system should be flexible $t \cap$ allow for

future incorporation of acyanced viagnostic concepts and rualuation techniques and systens.
5.5

The criterion may be satisfied in designs using a computer based system when either:

a) the design is expandabie to accept new functions.

or

b) the design a lows for the addition of processors, memories or additional computers, slich as in a distributed network.

This criterion may be satisfien by a hardwired system when:

a) the design allows for the addition of new displays to the SPOS panel/ worksoace.

nind

i) the design allows for the installation of eyuipment to support the displays.

The addition of diagnostic techniques must not compromise the primary SPDS function and is suhiect to review prior to imp lement at ion. 


\subsection{DATA SET}

A.2. 1 Busis of Parameter Selection

The bas is for seliction of

the minimum set of

parameter's in the primary

display shall be dacuinented

as part of the riesign.

\subsection{DATA VALIOATION}

4.3.1 Real Time Validation

Display dat a shall De

validated on a real time

basis where practicable.
5.5

This criterion is satisfied when:

it can be demonstrated that the

primary display format, using the

parameters selected meets the

guidelines or criteria of Section 3.

5.1

This criterion is satisfied by:

d) comparing redundant sensor readings prior to the display of the parameter.

6.7 .2 .7

or

b) using analytical redundancy among

different parameters and using models and equations that have been documented and validated. Operating regimes where the equations used are not valid should be identified and documented. 


\subsubsection{Unvalidated Data}

Display oata which is unvilidated shall be so

indicated to operators.
5.1

This criterion is satisfied when:

a) validated parameters, unvalidated parameters, and invalid data ore identified, where practical

and

bi validated parameters are coded in a manfier whereby they are easily tist ingutshed from unvalidated parameters.

Ainc

c) coding of invalid data is distinet from the coding of data for which data validation is unsuccessful.

and

1) aperating procedures for lise of the SPOS provides guidance for treatment of invalid data and resolution of unsuccessful data validation.

and

e) operator training in the use of the SPOS includes practice in dealing with unvalidated data and application of procedures to resolve unsuccessful data validation.

Operator knowledge of the validity of data is important in correctly assessing the safety status of the plant.

\section{7 .2 .7}




\subsection{OISPLAY}

4.4.1 Design Principles The display format shall be designed to accepted humdn factors principles.

\subsubsection{Parameters 0isplayed}

\subsubsection{T Individual Parameters} The primary display may be a continuous

indication of individulal plant parameters or may be composed of a number of measured variables or ser!ved variables.
This criterion is satisfied when:

a) the design conforms to the display guidelines presented in NUREG 0700,

and

1) the primary display format conforms to the generat criteria in Section 3.

5.7

5.5

This criterion is satisfied when:

a) a dedicated display, such as a CRT, with a cingle primary display format cont inuousty displays the minimum parameter set necessary to assess the safety stakus of the plant.

b) reduction in size of the primary display format is provided when it is necessary to display secondary information.

c) audio or visual cues are provided by the system to alert a well trained operator to return to the primary display format while viewing secondary information.

or

d) the seismifally qualified, concentrated backup display of primary format infromation is visible to the operator while viewing secondary information on the CRT.

\section{7 .2}




\subsubsection{Timeliness and Accuracy} of Data

Displayed data shall precent current and accurate status of the plant.
5.1

This criterion is satisfied when:

a) the sampling rate for each parameter is chosen such that there is no meaningful loss of information in the data presented to the operator.

and

b) the time delay from when the sensor signal is sampled to when it is displayed is no greater than 2 seconds.

and

c) maintaining the control room SPDS display is given processor priority over display and processing requests from the TSC, EOF, or other sources.

and

d) each parameter is displayed with an accuracy sufficient for the operator to discriminate between abnormal conditions which impact safety and normal operating conditions. 


\subsubsection{5cope of Data}

The display should be responsive to transient and accident sequences.
This criterion is satisfied when:

a) operator comprehension of a change in the safety status of the plant irom the primary SPOS display could be achieved in a matter of seconds. If closure of this task takes several minutes, the design is unacceptable.

and

b) the display system correctly portrays the plant process status for all design $b 75$ is events and events spec if ied by NUREG-073?,

Section I.C. I, Guidance for The

Evaluation and Development of

Procedures For Transients and Accidents 
4.4.3 Pattern and Coding

4.4.3.T Parameter Grouping

Parameters must be

grouped to enhance

operators asses sment of

the plant and to assist

in making functiona?

comparisons.
5.1

Tnis criturion is satisfied when:

a) the minimum set of parameters are presented on the single primary display format. The minimum set of parameters must be the ones by which the operator evaluates the safety status of the plant.

and

b) the parameters displayed are grouped so that all are visible to the operator within one field of view.

and

c) the parameters are sequenced in a lonical manner to facilitate operator comparison of parameters in evaluating the safety status of the plant.

and

d) the primary oisplay format utilizes patterns and display enhancements as discussed in Section 3 . 
4.4.3.2 Pattern and Coding Techniques

Pattern and coding

techniques shall be used

to ass ist operator

detection and

recognition of unsafe operating conditions.
5.1

criterion can be satisfied by:

a) the use of color coding to indicate the approach to unsafe operation and to indicate unsafe operation.

or

b) the use of limit marks for each parameter displayed. The limit marks should be representative of operational limits established by technical specifications, process limits, and safety system actuation setpoints, if app?icable.

c) the use of patterns which noticeably distort when an unsafe condition is approached.

Also see Section 3.3, Display Techniques. 


\subsubsection{Additional Data}

4.4.4.1 Magnitude, Trend

The display shall be capable of presenting magnitudes and trends of parameters or derived variables. The display of time derivatives in lieu of trends may be accept ab le.
5.1

This criterion is satisfied when:

d the primary display "ormat contains the magnitude for all variables being displajed.

and

b) the prifiary display format has the capability of indicating trends, or trends of operator selected parameters are available in a secondary display format.

and

c) trend data is displayed with sufficient resolution in time and magnitude to ensure that rapidly changing parameters are accurately displayed. The frequency bandwidth of the signal measurement system, consisting of sensor, signal processing devices and trend display device should be broad enough to transmit all meaningful information of the measured parameter or derived variable.

The display of time derivatives of variables is acceptable only when the derivatives unambiguousiy reflect the trends in the variables. The algorithm used for time derivatives must be adequate to track oscillating plant variables that may exist during the design basis events for the plant.
6.7 .2 .1

6.7 .2 .8 


\subsubsection{Recall Capabilities}

The recall of additiona?

data on secondary

formats or displays is

desirable.
5.5

This criterion is met when:

a) operator requests to the display system will result in displays, of addit ronal data, on secondary formats, such as trend data of the safety status parameters.

and

b) data is available for retrieval and is not lost as a result of an electrical power $f$ ai lure.

and

c) data stored for retrieval is stored on a secure medium and is available upon demand.

and

e) response times to operator requests for information on secondary displays conforms with NUREG-0700 guidelines for computer resporise tiniz to operator queries.
6.7 .2 .8

6.7 .1 .7 
4.4.5 Mode of Operation 4.4.5.1 Mode of Plant operation The design of the display shall contain a single primary display format for each mode of plant operation.
This criterion is satisfied when:

a) the design contains a primary display format for each mode of plant uperation defined by the technical specifications of operation.

A common display format composed of the sane parameters may be used for several modes of plant operation. However, for any one mode, the display must contain that

minimum set of parameters needed to assess the safety status of the plant.

Typical modes of plant operation are:

1. Power Operation

?. Startup

3. Hot Standby

4. Hint Shutdown

5. Cold Shutdown

6. Refueling 


\subsubsection{Displav. Fornat Selection}

For each plant operating mode, display formals may either be automatically displayed or manually selected.

\section{5}

his criterion is satisfizd when:

a) a manually operated switch or is put from an alpha-numeric keyboard, touch panel, light pen, cursor, or equivalent interface is provided by the design to allow the operator to adjust the display format for the mode of plant operations.

or

b) an automatic display format change occurs with a change in the mode of plant operation.

Automatic change must be designed so that gradual change due to an abrormal condition is not interpreted as a change in mode of operation. There must also be provisions to indicate to operators that a change in the mode of plant operation has occurred. Provisions must be included for the operator to override automatic change when necessary.
6.7 .1 .1 


\subsection{LOCATION AND READABILITY}

4.5.l Display Location

The SPOS rhali be located

in the control room with

additional displays

provided in the TSC and ECF.

\subsubsection{Control Board}

If the SPDS is part of the

control board, it must be

easily recognizable and

readable
This criterion is satisfied when:

prcuisions are made for locating the SPDS display and associated controls

in the control room, TSC, and EOF.
This criterion is satisfied when:

a) the SPUS is readily istinguished from other displays on the control board.

6.1

and

b) the display conforms to the appropriate display readability guidelines stated in NUREG 0700.
6.8

6.7 .2 


\subsubsection{Display Readability} The display shati be readable from the emergency station of the Senior

Reactor Operator.

\section{and
b)
c)
and
d)
and
a?
and
f}

and acceptably low flicker and noise.

This criterion is satisfied when:

a) the display design conforms to the appropriate display readability guidelines stated in NUREG-0700, such as viewing distance, viewing angle, and screen location for standing and seated operators at the Serijor Reactor Operator's Station.

and

c) Alpha-numeric characters generated with a $7 \times 9$ dot matrix or larger are preferable; characters with $5 \times 7$ dot and matrix are acceptable, if necessary.

d) density of display is less than $25 \%$ when complex symbology le.g.mimics are displayed.

2) for ease of detection, acceptable symbol to hackground contrast. ratio should fall in a range of $3: 1$ to $4: 1$ for all important data,

f) motion of vata displayed on a CRT to prevent screen burnolit is at a rate slov enough to avoid distracting the operator.
6.7 .2 .1 


\subsubsection{0isplay Accessibility}

The display shait be readily accessible and visible to the

Shift Supervisor

Control Room Senicor Reactor

Operator

Shift Technical Advison

One Reactor Operator.
This criterion is satisfied when:

a) phsyical obstructions do not block a person's field of view when tno person is at tho norma? work station.

\section{and}

b) if the Sbos is not in the operator's direct field of view at the workstation, a ruorientation of his/her field of view allows viewing the 5 plos from the workstation.

and

c) members of the control room operating Elow have physical access to llie SPDS from their normal workstition. For example, a short direct walk to the SPOS is acceptable.

d) glare from nornal or emergency lighting does not restrict vieining of the SPD: srom within the control room. The usc vi antiglare techniques and devices are acceptable when they are in accory with other criteria stated in this report.

and

e) luminance levels and luminance contrast do not limit viewing from locations throughout control roon.
6.1 .1

6.1 .5 .3

6.7.2.1 


\subsubsection{Control Accessibility} The display system shall not interfere with the n rinal movement of the control roam operation crew. The display system shall not interfere with full visual access to other control room operating systems and displays.
This criterion is satisfied when:

a) the aisplay system does nut obstruct the norinal movement of the control

6.1 .1 room operating crew.

and

bi the displa. system coes not interiere with the full visual access to other control room operating systems and displays. 


\subsection{STAFF}

\subsubsection{Control Room Staff}

No additional oper at ing

staff other than the normal

control room operating

staff should be needed for

operation of the display.

\subsubsection{Operator Interaction Flexibility to allow for interaction by the operator is desirable in the design of the display designs.}

\subsection{This criterion is satisfied when:}

a) no additiona? operating staff other than the normal control room operating staff need be added for aperation of the SPDS.

and

b) the operator training program contains instructions on the use of the SPDS.

and

c) an SPDS user's manual is available for and operator reference in the control room.

d) interaction with an SPDS computer is designed such that training in computer programing is not renuired.

This criterion is satisfied when:

a) the system contains operator

\subsection{T. 4}

and interacti:? devices.

b) the display system positively acknowledges each request that the and design allows the operator to make.

\section{7 .1 .7}

c) system response times to operator request conform to the guidelines of NUREG 0700. Undue time delays in response to a request are unacceptable. Function keys for the recall of data are the preferred type of interactive devices. Keyboards are acceptable for use in the recalling of data provided the necessary syntax is simple and straightforward to use. Alpha-numeric keyboards added to SPDS should have the same keyboard layout as other keyboards in control room. Other interactive devices such as touch pariels or -27 - 


\subsection{PROCEDURES}

4.7.i Failure Recognition

The control room operations staff shall be provided

with sufficient information

and criteria ior

performance of an

operability evaluation of the :PDS.
This criterion may be sat isfied by:

a) designing a monitoring system in the display" which may be automatic or

6.7 .2 .6 operator act vated.

b) a display of calendar date and time of day, with some means of indicating the passage of seconds. The display

should be updated only when the system is operating properly so that a static time would indicate a system failure.

The data and time should be located in a corner of ihe display so as not to distract the operator.

$\mathrm{Or}^{\circ}$

c) the operable status of the disolay system is available upon operator demand.

or

d: an equivalent rieans of evaluating display system operability is ava'lable.
6.7 .2 .7

6.5 .1 .1 
4.7.2 rechnical Specif ic ation A technical specif ication of operations is required to define compensatory measures for the operator when the SPOS is inoperable.
5.6

This criterion is satisfied when:

a) the technical specification defines acceptable compensatory measure for each function performed by the SPOS.

The use of the seismic qualified back-up display, monitored on a frequent basis, may be an acceptable compensatory measure. The same minimum set or comparable set of safety status parameters on the SPDS primary display format should be present on the backup. Also, the backup display must be readily interpretable by the operator. 


\subsection{AUDIBLE ALARMS}

Where feasible, the SPOS should

include some audible notification to alert personnel of an unsafe operating condition.
5.5

This criterion is met when:

a) the display system enits a distinct audible sound, such as the beeper available on computer terminais, upon detecting an abnormal operating condition.

and

b) the SPDS alarm system has provisions to silence, acknowledge, reset and est these functions, as appropriata.

An audible alarm from the SPOS nced not meet the inteiss ity requirements given in NUREG-0700.

SPOS alarms should be independent of the annunciator system and should not result in the generation of the same audible alarms as the annunciator system.
6.2 .2

6. 3.2

6. 3.4 


\subsection{DESIGN CRITERIA}

4.9.1 Functiona] Qualification A functional qualification program should be established to demonstrate SPDS

operational conformance with the functional design

criteria. and

This criterion is satisfied when:

a) a test plan is available for the display system. The test plan shall define a minimum of one test case for each major functional criterion of the display system. The object of the test case is to illustrate the correct performance of the implemented design.

b) a test report containing the results of the test cases is compiled. All major functional criteria must be tested successfully.

and

c) all display formats in the design are tested, including mode dependent formats.

and

d) a human factors review of the SPDS in accordance with appropriate portions of NUREG-0700 is performed with results evaluated in accordance with the guidel ines presented in NUREG 0801. The results of this effort are to be documented by the licensee/applicant as part of the control room design review.

and

e) a trained control room operating crew can effectively use the SPDS to detect abnomal plant operating conditions which impact safety. 


\subsubsection{Backup Displays}

Gisplays designated as a seismicaliy qualified backup to the SPOS must be designed to accepted human engineering principles.
5.6

This criterion is satisfied when:

a) the back-up displays contain the same minimum set of safety status

parameters as presented in the primary display format of the SPDS or an

equivalent comparable set of safety status parameters.

and

b) the back-up display is capable of operating during and following earthquakes, to the same degree as control room displays needed to comply with Regulatory Guide 1.97.

and

c) che needed seismicially qualified displays are concentrated into one segment of the control board.

Dependence on poorly human-engineered Class IE seismically qualified instruments that are scattered throughout the control room is not acceptable.

d) the backup displays, when reviewed as a group, conform with the guidelines of NUREG-0700.

and

e) meters on the control board which are part of the SPOS backup display ara readily identified and are not likely to be confused with 5 imilar meters in the vicinity. 


\subsubsection{Primary Display, Seismically} Qualified

it is preferred that only one display system be used for evaluating the safety status of the plant. ilowever, an alternative is to design the overall SPDS function with a primary and a backup display.
5.6

When the option for a seismically qualified primary disp?ay is selected, this option is satisfied when:

a) the design of the primary display conforms to Regulatory Guide 1.97, Revision 2, December 1980,

"Instrumentation For Light-Water Cooled Nuclear Power Plants to Assess Plant and Environs Conditions During and Following An Accident"

and

b)

the design conforms to the acceptance criteria defined in this report, with

the exception of the context of Section 4.9.2, Backup Displays. 


\subsection{HUMAN FACTORS ENGINEERING REVIEW PROCESS}

The human factors review for the Safety Parameter Display System will consist of two phases. The phases are:

(1) Review the design;

(2) Review the functional operation of the system;

Details on each of these phases are presented in the following text.

\subsection{Review of Verification of Design}

The major steps in reviewing the design are:

(1) Evaluate the process used by the licensee/applicant to verify the design.

(2) Audit the functional conformance of the design against functional criteria stated in Section 4 , Specific SPOS Design Review Acceptance Criteria.

(3) Audit the design's conformance to the acceptance criteria stated in Section 3, General Acceptance Criteria for SPDS CRT Displays, and Section 4, Specific SPDS Design Review Acceptance Criteria.

(4) Audit the functional qualification tost plan.

In evaluating the process used by the licensee/applicant to verify the design, the staff will assess the adequacy and thoroughness of the design verification process. This effort involves an assessment of the type of activities performed by verifiers, the design discrepancies found, and how these discrepancies were resolved. This allows the staff to determine how we 11 versed the verifiers are with the functional criteria of NUREG-0696 and to determine the quality of the original design effort.

The type of design disc epancies established by the verification process will also be assessed to determine if à generic pattern exists among them. The purpose of this effort is to determine if the discrepancies are random ar are inherent to the design process. The discrepancies which are inherent to the design process have a much greater significance with respect to the actions needed to achieve an acceptable design. Should a generic pattern among the discrepancies be detected, the staff may determine that the design is unacceptable.

Subsequent to the evaluation of the verification process, the staff will conduct audits of the design. The depth and scope of the audits will be dependent upon the evaluation results, the functional criteria of NUREG-0696, and the acceptance criteria def ined in Section 3, General Acceptance Criteria, and Section 4, Specific Acceptance Criter: of this report. The test plan for qualifying the as-built system shoula also be audited.

In conducting the audit, the NRC reviewer should first select a sub-set of the functional guidelines of the design. As an audit is planned, the sub-sat of functions chosen should as a minimum be no less than 10-15\% of the total set. A different set of functional guidelines should be selected for each design reviewed. The second step is to audit the design to ensure that these functions have been incorporated into the design. Then the following steps 
are to audit the design to ensure that it meets the acceptance critoria for the functions selected. The final step is to audit the test $p$ lan to ensure that all of the selected functions are being fully tested.

Should the audit process define serious design discrepancies, then a Safety Evaluation Report should define the nature of the discrepancies and why the design features are unacceptable. Conversely, for acceptable designs, the Safety Evaluation Report should define the basis for acceptance along with the scope and depth of the review.

\subsection{Review of Validation of Functional Operation of the System}

The major steps in reviewing the functional operation of the systen are:

(1) Evaluate the procoss used by the licensee/applicant to validate the design.

(2) Audit test results for confarmance with the validated design.

(3) Audit the as-built system for conformance with the acceptance criteria.

In evaluating the process used by the 1 icensee/applicant to validate the design, the staff will assess the adequacy and thoroughness of the design validation process. This effort involves an assessment of the type of activities performed by the validators, the design and test discrepancies found, and how these discrepancies were resolved by the 1 icensee/applicant. This allows the staff to determine how well versed the validators are with the functional criteria in section 4 of this report, the acceptance criteria of this report, and the requirements of the test plan. Should a generic pattern among the discrepancies be detected, the staff may determine that the design is unacceptat?e.

Subsequent to the evaluation of the validation process, the staff will conduct audits of the validated design. The depth and scope of the audits will be dependent upon the type of deficiencies found during the validation process, the functional criteria of NUREG-0696, the acceptance criteria stated in Section 3, General Acceptance Criteria for SPOS CRT Displays, and Section 4, Specific SPDS Design Review Acceptance Criteria, and the test plan.

Should the audit process define design or test discrepancies, then the Safety Evaluation Report should define the nature of the discrepancies and why the design/test feature is unacceptable. Conversely, for acceptable designs/test results, the Safety Evaluation Report should clearly define the bas is for acceptance along with the scope and depth of the review.

\subsection{Review Methods}

The reviews described in Section 5.1, Review of Verification of Design, and in Section 5.2, Review of Validation of Functional Operation of the System, each have two specific levels. The first level of review evaluates the processes used for verification and for validation. In the second level of review, an audit assesses specific features of the design. 
To conduct these reviews, the staff will need:

(1) A description of the verification and validation program for the SPDS.

(2) The results of the verification and validatigil program.

(3) Access to or subnittal of the SPOS design, test pian, and test results.

The staff will evaluate the program for the results of the design verification and validation. The staff will also audit the design, audit the test plan, and audit the test results. These audits could take the form of:

(1) Assessing submitted azterial.

(2) Assessing material at the plant/vendor site.

(3) Assessing material obtained electronically from the utility or vendor.

The first two forms have been traditional methods usad by the staff. The third form is currently technically feasible and holds the potential for cost savings to the regulatei as well as regulators. However electronic transmission of material woulo require significant changes in the regulatory process.

The staff $p l a n s$ to conduct all of the above defined reviews in a single effort. All of the material needed to conduct the review is to be available prior to starting the revieis. Upon completeion of the review, the NRC staff plans to publish their findings in a Safety Evaluation Report. This review plan mimimizes staff resource requirements as only one review effort is made instead of the usual two. Industry commerits in this review plan are welcome. 


\subsection{REFERENCES}

1) U.S. Nuclear Regulatory Commission, "Functional Criteria for Emergency Response Facilities", NUREG-0696, February 1981.

2) U.S. Nuclear Regulatory Commission, "Guidelines for Control Room Design Reviews", NUREG-0700, September 1981.

3) Ramsey, H. R. and M. E. Atwood, "Human Factors in Computer Systems: A Review of the Literature", SAI-79-111-DEN, September 1979.

4) Seminara, U. L. and S. K. Eckert, "Human Factors Considerations for Advanced Control Board Design", EPRI MP-1118, Vol. 4, March 1980.

5) Banks, W. W. and M. T. Clark, "Some Human Engineering Color Considerations 'Jsing CRT Displays: A Review of the Literature", EGBG Report SD-B-81-C0I.

6) Banks, W. W., et al., "Human Engineering Design Considerations for CRT Generated Displays", EG\&G DRAFT REPORT.

7) Danch.i:, M. M., "Techniques for Displaying Multivariate Data on Cathode Ray Tubes with Applications to Nuclear Process Control", NUREG/CR-1994, EGQG-2086, Apri 11981 .

9) Bruckner, L. A., "Oa Chernoff Faces", in P.C.C. Wang, Graphica1 Representation of Multivariate Data, New York, Academic Press, 1978, p. 93.

10) U. 5. Nuclear Regulatory Commission, "Methodology for Evaluation of Emergency Response Facilities", NuREG-0814, August 1981.

11) U.S. Nuclear Regulatory Commission, "Evaluation Criteria and Acceptance Guidelines for the OCRDR", NUREG-0BOT, Oc tober 1981. 
APPEND'X-A

\section{APPLICATION OF GENERAL CRITERIA TO OISPLAY PATTERNS}

The purpose of this Appendix is to provide guidance in the application of the General Acceptance Criteria. Th is Append ix is not intended as an endorsement of the display techniques presented.

A recent report (Ref. 7) presents numerous ways of displaying multivariate data for use in nuclear process control. Although this report draws some conclusions on the appiicability of various displays for process control, these conclusions do not necessarily apply to the SPDS functional

requirements. Many of the display techniques presented would be acceptable for the SPOS primary display format provided they are designed to sat isfy the functional requirements of NUREG-0696.

The following are a selection of display techniques, primarily taken from Reference 7 , which are presented and reviewed in accordance with the criteria set forth in the previous sections.

\section{A.1 Bar Chart}

The bar chart, Figure 1, synthesizes an array of analog meters. Eac, bar represents a specific parameter. The length of each bar is generally proportional to the magnitude of the measured parameter it represents. The reactor operator can easily associate with this type of display because of the multitude of analog meters in the control room used to display the magnitude of operating parameters.

Each tar on the display has a unique identification label. The label provioes a positive identification of the parameter each bar represents. While an operator might learn the positions of each parameter bar, the labels provides a reference identification of the parameter that is aiways available for the operator's use. It would nat be acceptable for an operator to have to memorize the position of each parameter on the display.

The bar chart, as presented in Figure 1, would not, by itself, allow a quick assessment of the plant safety status. Each bar has a different length. There is no display enhancement to distinguish norinal parameter values from abnormal ones. A small change in any one bir indicating the onset of an abnormal cond $i$ ion might not be detected by the reactor operator.

An acceptable enhancenent to the bar chart would be to provide a raference to the normal operating condition. With references showing normal parameter operating values, the operators are more likely to notice deviations from normal conditions. This enhancement might include an indication 0 . the normal value of each parameter together sith pointers for the normal operating range of each parameter. Such indications would facilitate interpreting the importance of a parameter change. 
The scaling of the magnitude of each parameter displayed may be changed so that under normal conditions each bar is of the same length. When each bar is the same length during norma operating conditions, as shown in Figure 2, a change in any ore bar becomes more noticable. A bar chart such as figure 2 would be acceptable to satisfy the requirement for a quick assessment of plant safety status proyided abnormal values of each parameter produce noticeable ctanges from the normal value.

Other enhancements which improve the ability of the operator to identify an abnormal condition would also be acceptable. The labels or bars may change colors to signify an abnormal condition. Blinking of a label is also acceptable to call attention to an out of range parameter. These types of enhancements can be added to most display patterns to assure detection of abnormal operating conditions.

\section{A.2 Deviation Bar Chart}

The deviation bar chart, Figure 3 , is similar to the bar chart discussed above. However, each displayed bar consists of the difference between the measured value of the parameter and the normal value of the farameter. Note that while the magnitude of the parameters measured are always positive, the deviations from the normal value $c$ an be either positive or negative. A parameter which deviates significantly from its normal value is easily detected by the operator.

Like the bar chart, each parameter is uniquely identified. Thus a change in one deviation is readily associated with the corresponding parameter. There is a direct association with the status of the plant since under normal conditions the deviations are small. In the event of an abnormality, the magnitude and direction of a parameter change is readily determined.

The choice of scaling for the deviations is important in assuring that there is a distinct difference between normal and abnormal conditions. Deviation bars that can vary over the ent ire display range under normal conditions would be unacceptable. The range of normal condition deviat ions should represent no more than $10 \%$ of the total range provided to display deviations. An indication of the normal range for each deviation is acceptable.

Some means of indicating the magnitude of each parameter is needed with the display for use a primary SPDS display since this information is not included in the deviation bar chart.

\section{A. 3 Linear Profile}

In a 1 inear profice, the wide bars in the bar chart are replaced by thin lines. As presented in Ref. 7 , percent range is displayed vertically and the individual parameters are defined and spaced horizontally. The vertical height of the parameter line represents the magnitude of the parameter. The end points of each parameter 1 ine are connected to establish a profile line, Figure 4. Abnorma operating conditions are generally represented by an irregular profile line. Labels are provided along the bottom to identify each parameter. 
Scaling considerations $f_{1}$ - the linear profile are the same as for the bar chart. A horizontal l ine, representing normal operating conditions superimposed on the display is an acceptable enhancement.

Shading below the profile $l$ ine is also acceptable to provide a more distinguishable profile.

\section{A.4 Circular Profile}

In a circular profile, the parameter lines of a linear profile join in a common origin. Parameter lines radiate from the origin with equal angular spacing relative to each other, Figure 5 . The length of each line represents the magnitude of the parameter. Under normal operating conditions the profile should be circular. An irregular profile is indicative of an abnormal operating conditions. Labels are provided to identify each radial line.

Shading within the profile is acceptable to enhance the operator's perception of plant status.

\section{A.5 Time History Plot}

A time history plot, Figure 6. provides a continuous graph of past values of a parameter vs. time. This display technique incorporates trend information into the display. When a parameter becomes abnormal a history of the abnomality is readily apparent. The trend should be a straight line, with possible minor fluctuations, during normal conditions.

It is acceptable to display the minimum parameter set using several pists, each plot containing one or more variables. When more than one parameter is presented in a plot there should be means of identifying each inividual parameter. Color coding of traces is acceptable. Color codes used, however, must not conflict with other uses of color in the display.

A display of two variables where the vertical ax is and/or the fiorizontal axis for each variable do not intersect, should be considered as distinct plots. In accordance with NUREG-0700, the number of parameters in one plot should not exceed five (5).

When more than one parameter is presented on each plat, then the grouping of parameters should emhance the operators assessment of the safety 5 tatus of the plant.

\section{A. 6 Chernoff Face}

The Chernoff face is a graphic technique which maps multivariate data into facial features. Changes in data are translated into a change in the facial expression. Figure 7 , shows an example of a Cherncff face. The assignment of facial features to paraneters is also shown in Figure?. 
Many linear and non-Tinear mappirgs reTate the dat a being disp fayed to the different facial features. Thus it is difficult to relate a change in the face to a specific change in the safety status of the power plant. There is not a direct association that an operator $c$ an make between the facial features and the magnitude of parameters or the safety status of the plant. Also, the Chernoff face does not allow simple identification of individual parameters. The frowning mouth shown in Figure 7 is a composite of three parameters. Extensive training and memorization of patterns are required to interoret these displays. Studies using Chernoff faces have shown that certain combinations of changes in the facial characteristics can result in a face that does not appear distorted (Ref. 8). Thus, there may not be a noticable distinction between normal and abnoimal conditions.

These characteristics make the Chernoff face unacceptable for use as the primary display of an SPDS.

\section{A.) Frurier Representations}

iwo other techniques presented in Ref. 7 are the $l$ inear and polar Fourier rebresentations.

A Fourier series is used to generate the function:

$$
Y=A_{1}+A_{2} \cos x+A_{3} \sin x+A_{4} \cos 2 x+\ldots
$$

whose

anc

$$
A_{1}, A_{2}, \ldots \text { are the parameters to be displayed }
$$

$x$ is an angle between 0 and $2 p i$.

The linear fourier plot representation is a plot of $Y=F(X)$ vs. $X$ using restangular coordinates. The polar Fourier plot ropresentation is a polar plat of $Y=F(x)$ vs. $\therefore$. The linear fourier plot representation is shown in Figure 8 .

The Fourier representations are complex nonlinear transformations where individual parameters are no longer presented in readily ident ifiable form. This it is not possible to associate the status of the plant with the

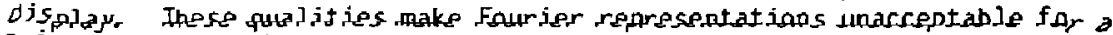
primary SPDS display. 


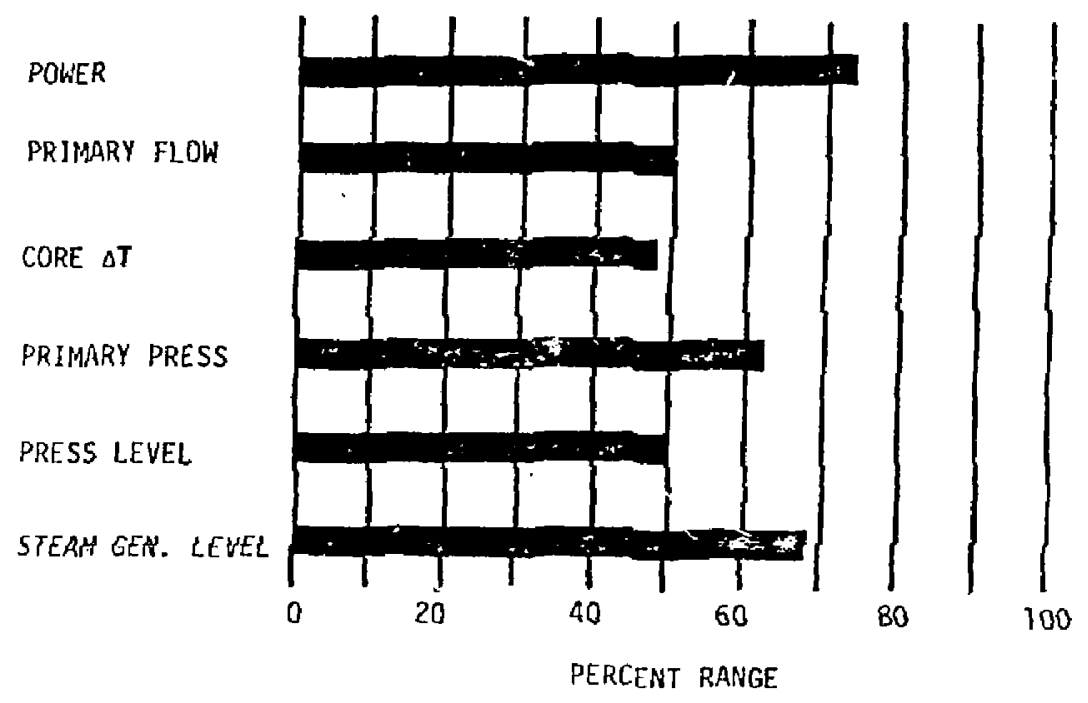

FIGURE 1. Bar Chart Display 


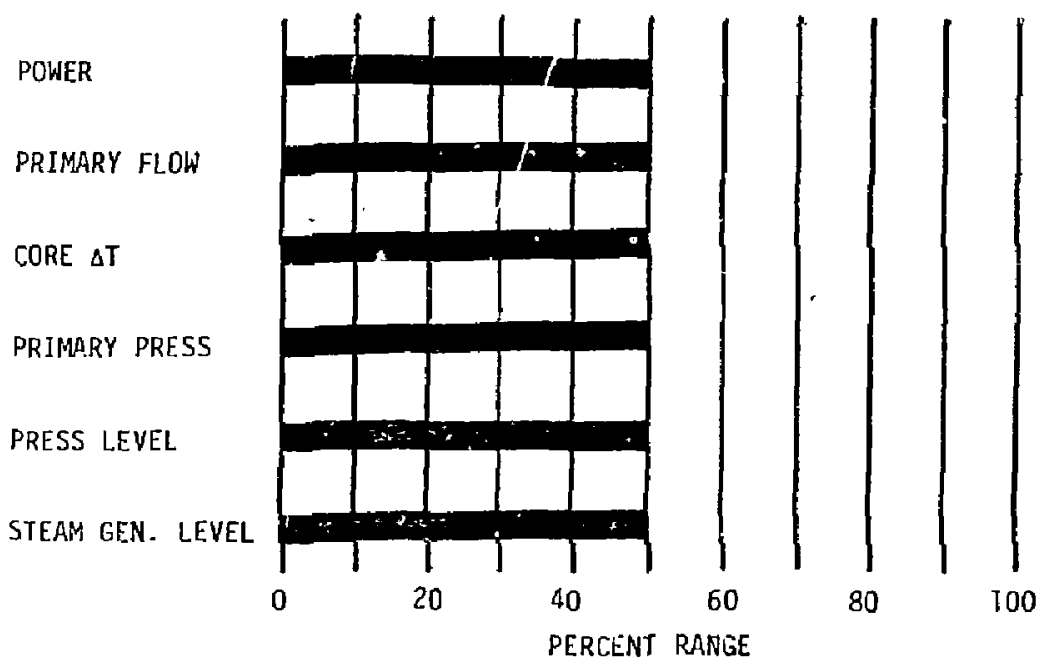

FIGURE 2. Scated Bar Chart Display of Normal Conditions 


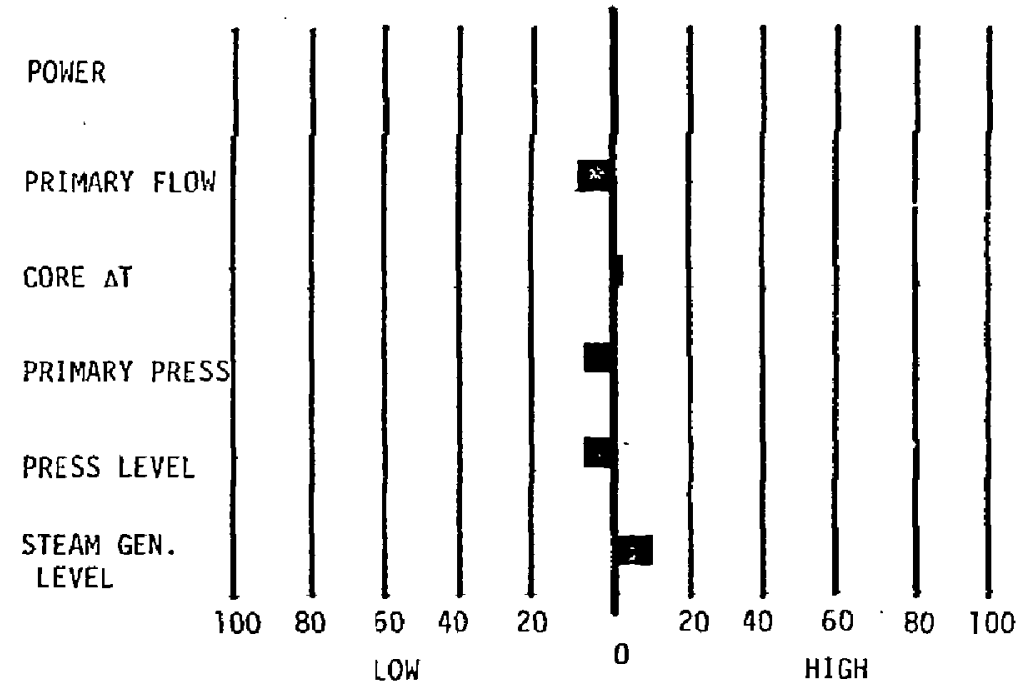

FIGUR! 3. Deviation Bar Chart Representatior. of Normal Operating Conditions 


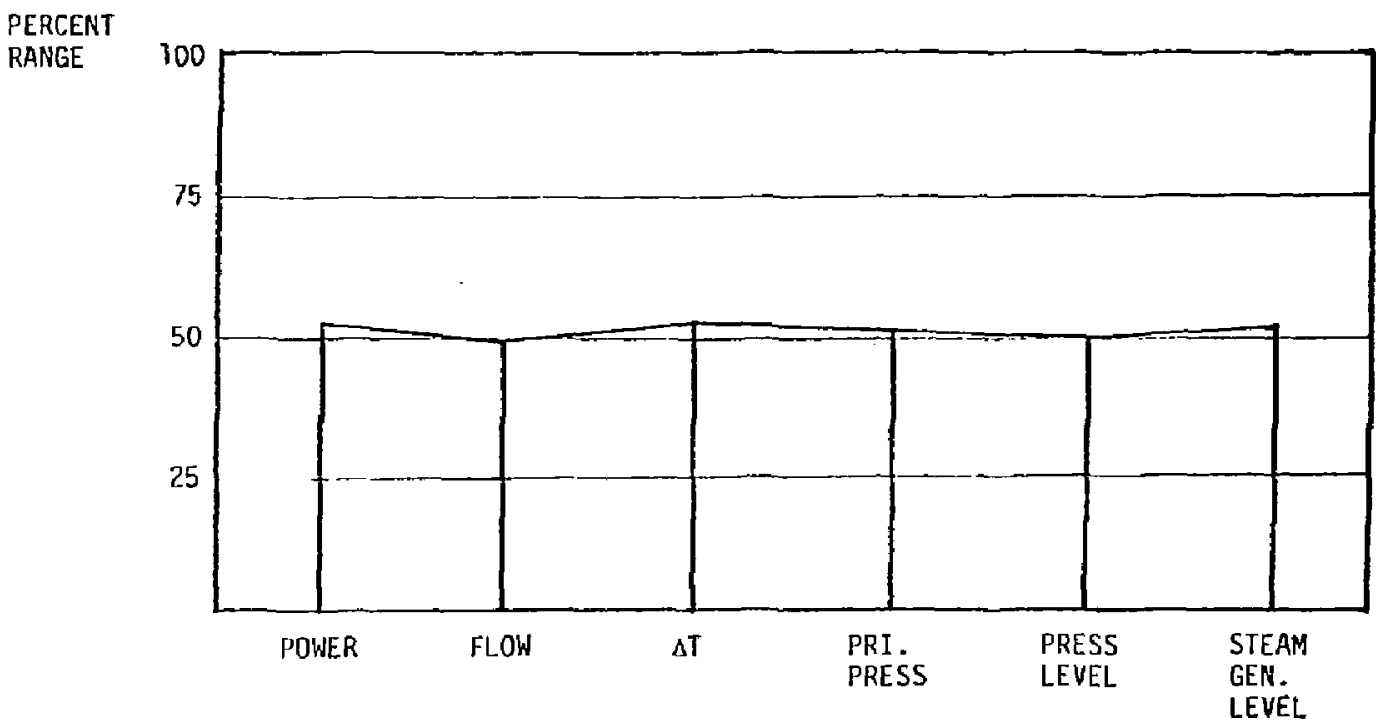

FIGURE 4. Linear Profile of Normal Dperating Conditions

A-9 


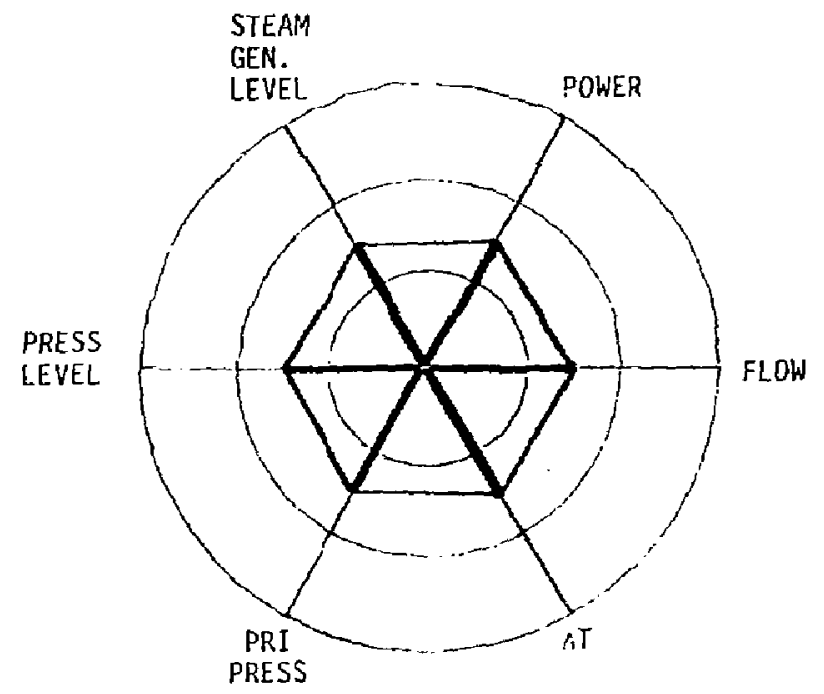

FIGJRE 5. Circular Profile of Normal Operating Conditions 


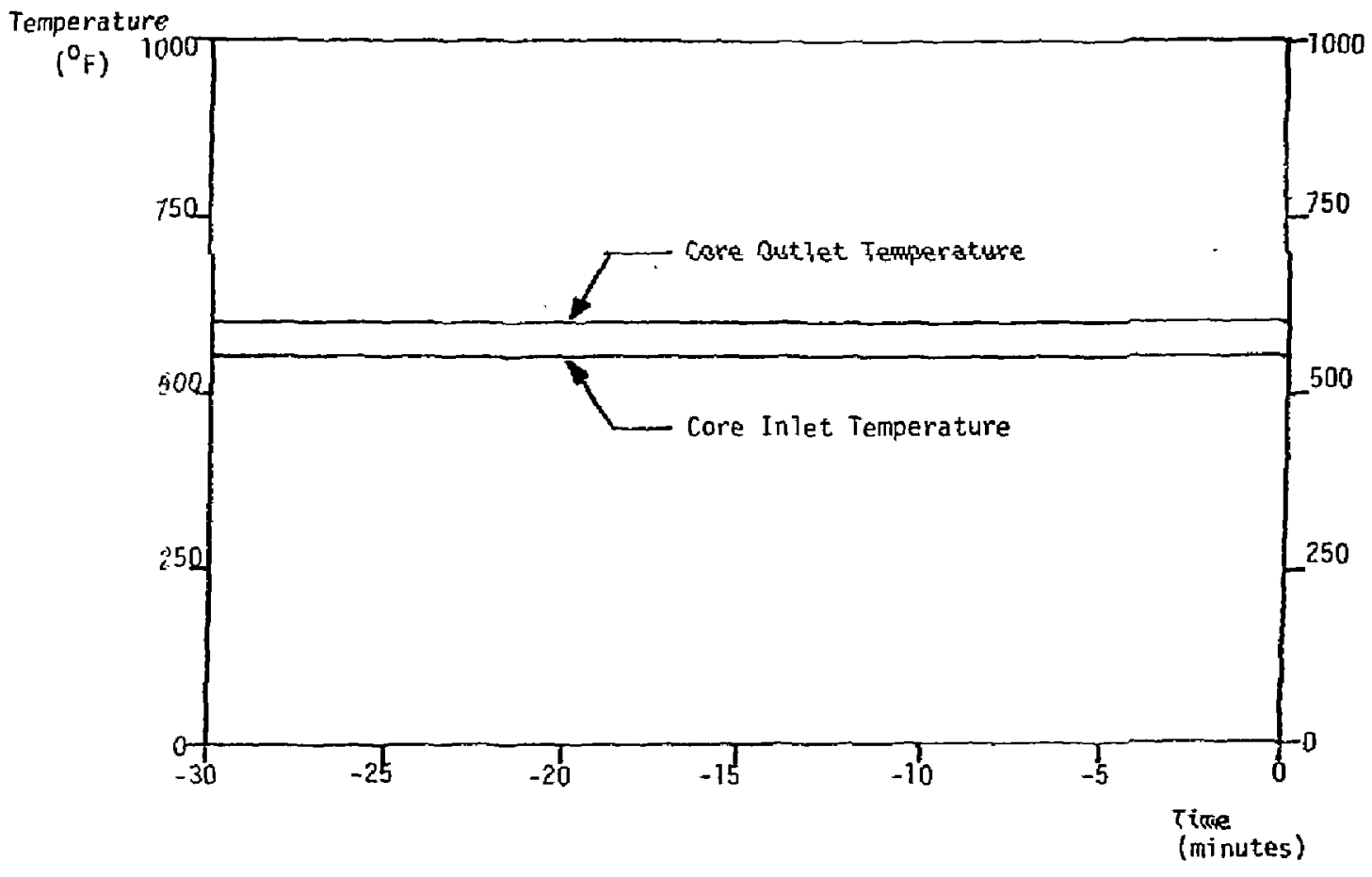

FIgURE 6. Time Histary Plot 


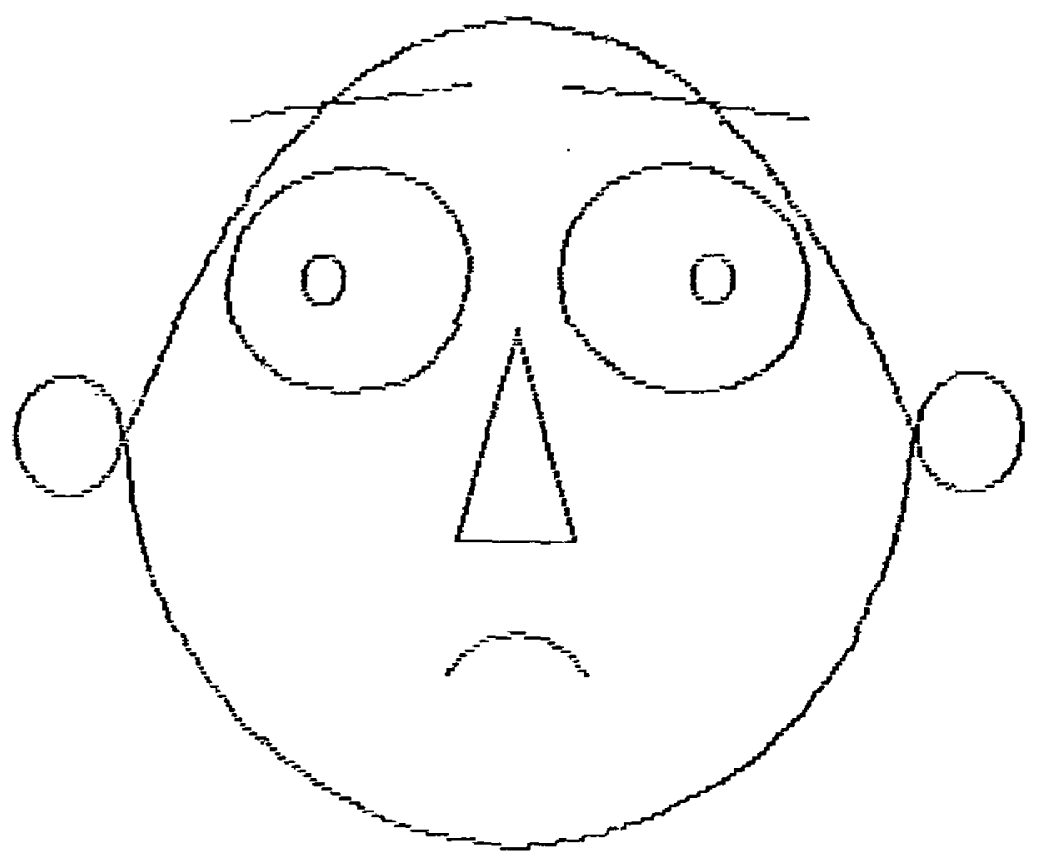

NOTE: THIS DISPLAY PATTERN UNACCEPTABLE FOR AN SPOS

Assignment of variables to facial features for Chernoff faces

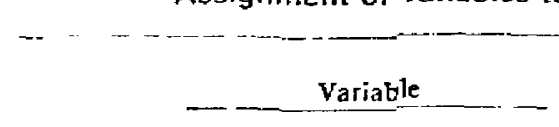

Power

Primary Flow

Cold Leg Temperature

Delta Temperature

Primary Pressure

Pressurizer Level

Secondary Pressure

Secondary Feed Flow

Steam Control Valve Position

Steam Generator Level

Condenser Pressure
Facial Feasure

Size (half Iength) of cyes

Slant of eyes

Eicentricity of eyes

Position of pupils

Scparation of eyes

Hight of center of eyes

Length of nose

Nose width

Curvalure of mouth

Length of mouth

Position of center of mouth

FIGURE 7 Chernoff Face Representation of an Abnormal Operating Condition 


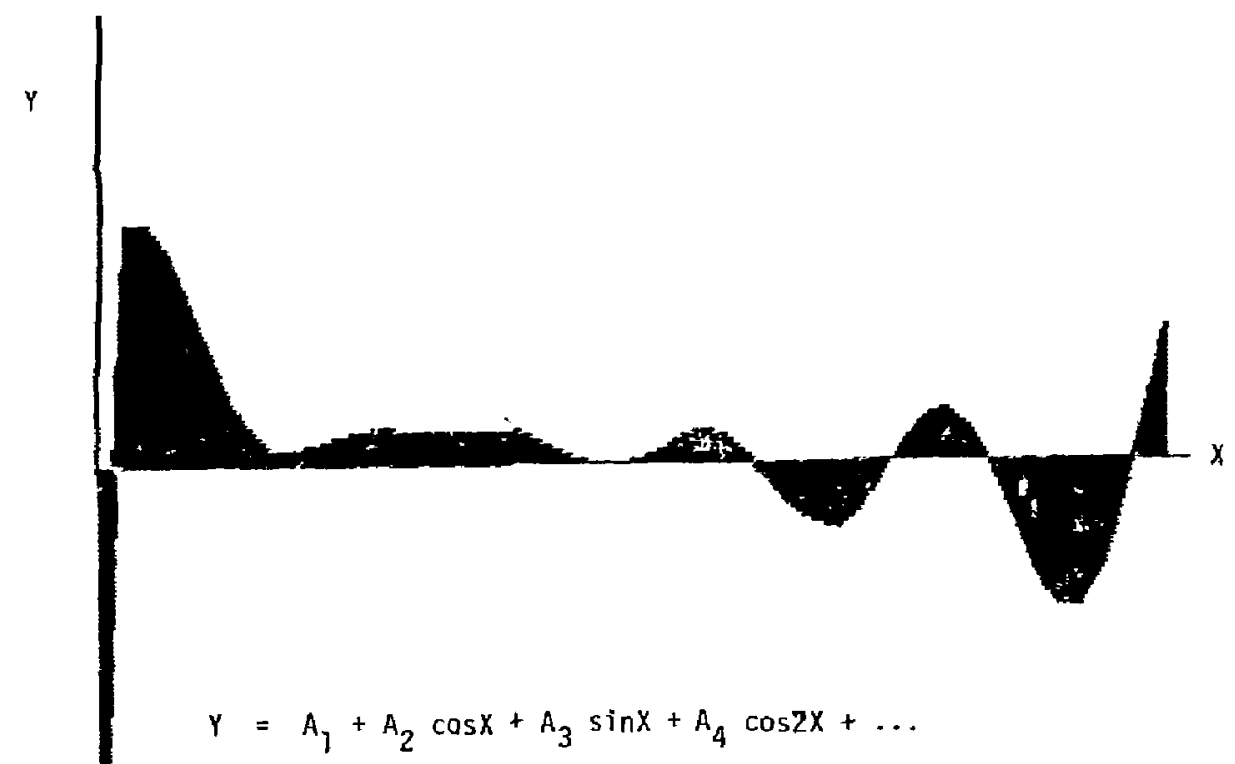

Where $A_{1}, A_{2}, \ldots$ are parameters

NOTE: THIS OISPLAY PAJTERN UHACCEPTABLE FOR AN SPDS

FIGURE 8. Linear Fourier Plot of Normal Operating Conditions 